\title{
On the Use of Thermal Properties for Characterizing Dimension Stones
}

\author{
Paulo Amaral ${ }^{1, a}$, António Correia ${ }^{1,2, b}$, Luís Lopes ${ }^{1,3, c}$, Paula Rebola ${ }^{4, d}$, \\ António Pinho ${ }^{3,5, e}$ and José Carrilho Lopes ${ }^{3,6, f}$ \\ ${ }^{1}$ Centro de Geofísica de Évora, Universidade de Évora, Portugal \\ ${ }^{2}$ Departamento de Física, Universidade de Évora, Portugal \\ ${ }^{3}$ Departamento de Geociências, Universidade de Évora, Portugal \\ ${ }^{4}$ Cevalor, LEM, Portugal \\ ${ }^{5}$ GeoBioTec, Portugal \\ ${ }^{6}$ Centro de Geologia da Universidade de Lisboa, Portugal

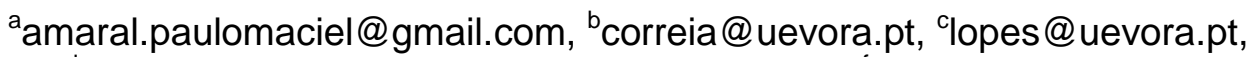 \\ dpaula.rebola@cevalor.pt, eapinho@uevora.pt, ${ }^{\dagger}$ carrilho@uevora.pt
}

Keywords: Dimension Stones, Heat Capacity, Thermal Conductivity, Thermal Diffusivity.

\begin{abstract}
The use of dimension stones in architecture and civil engineering implies the knowledge of several mechanical, physical, and chemical properties. Even though it has been usual practice to measure physical and mechanical properties of dimension stones the same is not true for thermal properties such as thermal conductivity, thermal diffusivity, specific heat capacity, and heat production. These properties are particularly important when processes related with heating and cooling of buildings must be considered. Thermal conductivity, thermal diffusivity, and specific heat capacity are related with the way thermal energy is transmitted and accumulated in stones; heat production has to do with the amount of radioactive elements in the rocks and so with the environmental impact of radioactivity and public health problems. It is important to start to measure on a routine basis those four thermal properties in rocks and, in particular, in dimension rocks so that their application can be improved and optimized. With this is mind three sets of different rock types (granites, limestones, and marbles) were collected to measure the thermal conductivity, the thermal diffusivity, and the specific heat capacity with the objective of characterizing them in terms of those properties. Since the same set of rocks has also been studied for other physical properties, a correlation amongst all the measured properties is attempted. For each rock type several samples were used to measure the thermal conductivity, the thermal diffusivity, and the specific heat capacity, and average values were obtained and are presented. As an example, for granites the thermal conductivity varies between 2.87 and $3.75 \mathrm{~W} / \mathrm{mK}$; for limestones varies between 2.82 and $3.17 \mathrm{~W} / \mathrm{mK}$; and for marbles varies between 2.86 and $3.02 \mathrm{~W} / \mathrm{mK}$. It is hoped that measuring thermal properties on dimension stones will help to better adequate them to their use in civil engineering as well as to adequate their use in terms of a CE product.
\end{abstract}

\section{Introduction}

The interaction between mankind and rock is very old. Rocks have been used by men for very distinct purposes such as symbolic artifacts, art, construction, architecture, as well as many others. Characteristics of rocks, such as durability, multi-purpose functionality, and availability make them an indispensable raw material for mankind. As many other countries in the world, Portugal is known for extracting and putting in the global market granitic rocks and marbles. Usually the value of a rock is related with its visual aspect and texture; however, many other properties have to be studied to understand rock quality and commercial value; in that respect the behaviour and response to physical, chemical, and mechanical factors is of the greatest importance. 
Beyond the simple description of a rock in terms of colour, texture and petrography, many other properties are measured for several purposes such as mechanical strength, flexural strength, bulk density, water absorption, open porosity, anchorage strength, coefficient of thermal expansion, abrasion, and impact strength. Even though it is not usual to measure thermal properties in dimension stones, which include thermal conductivity, thermal diffusivity, specific heat (or volumetric heat capacity), and heat production, they are important to define how they can be used for house climatisation and energy savings. As a matter of fact, rocks absorb and release thermal energy and, therefore, can be used during different times of the day to increase thermal indoor comfort. In this paper the results of measuring thermal conductivities, thermal diffusivities, and specific heat in several samples of granite, marble, and limestone are presented. No heat production measurements were performed on the samples described in this paper; however, heat production values are of great importance for public health studies since they are related with the concentration of radioactive elements in granitoid rocks such as uranium and thorium which produce radon that can be harmful if in high concentrations inside houses or apartments.

\section{Location and Petrography}

The seven rock samples of this study were collected in seven quarries in Mainland Portugal (Fig. 1). Samples G1, G2, and G3 were collected in quarries owned by Granimarante Lda.; samples C1, C2, C3, and M1 were collected in quarries owned by Joaquim Duarte Urmal \& Filhos Lda. Three of the samples are granites (G1, G2, and G3), one is marble (M1), and three are limestones (C1, C2, and C3) as it is shown in hand samples (Fig. 2) and confirmed by microscopic study (Fig. 3).

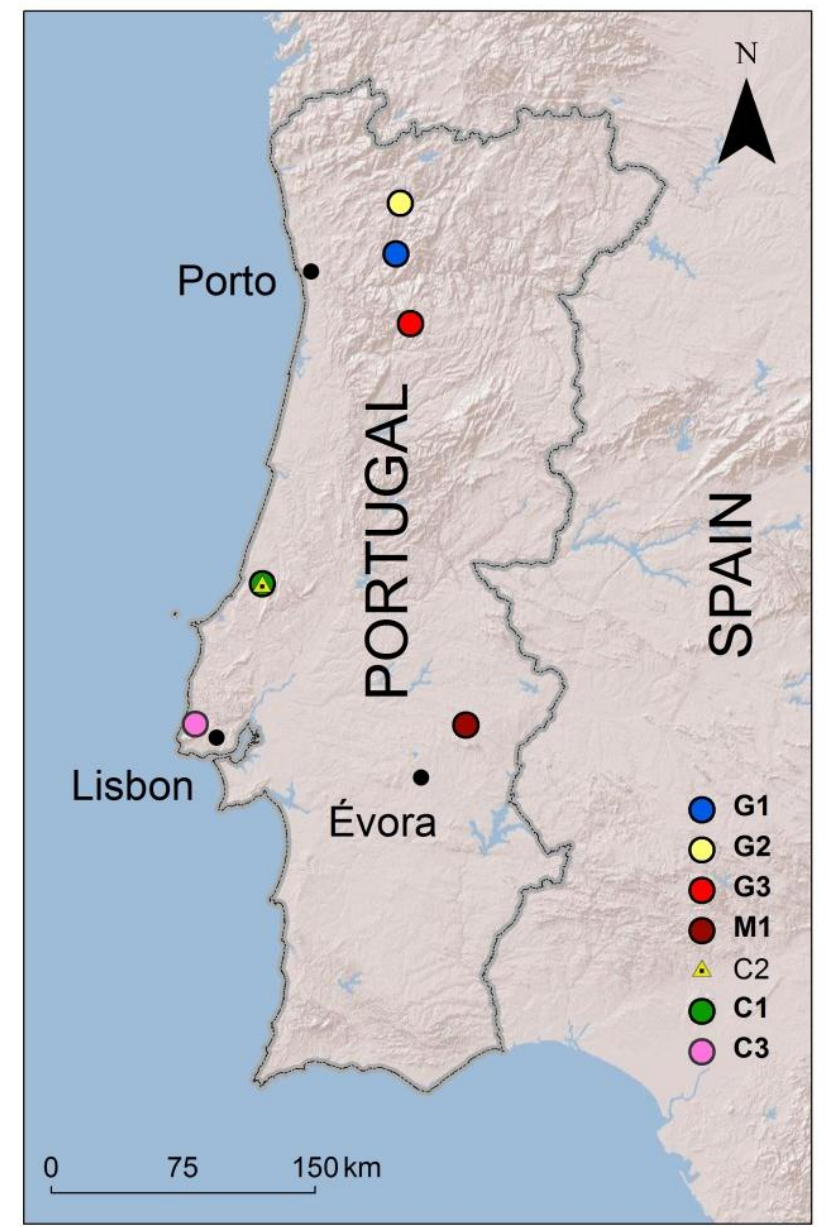

Fig. 1 - Location of quarries where the samples of the study were collected:

G1 - "Granite Tipo Pidre", Gondar, Amarante, Porto;

G2 - Granite "Cinzento Cristal", Cabeceiras de Basto, Braga;

G3 - Granite "Castro d'Aire", Castro D’Aire, Viseu;

C1 - Limestone "Vidraço Moleanos", Prazeres de Aljubarrota, Alcobaça, Leiria;

C2 - Limestone "Moleanos Azul", Prazeres de Aljubarrota, Alcobaça, Leiria;

C3 - Limestone "Lioz Dourado de Pêro Pinheiro", Terrugem, Sintra, Lisboa;

M1 - Estremoz White Marble, Estremoz, Évora.

All granites are leucocratic rocks (mafic minerals represent less than $30 \%$ in volume). G1 facies (Fig. 2) has a yellowish gray tone reflecting low to moderate degree of alteration (with loss of iron from biotite), while G2 (Fig. 2) and G3 (Fig. 2) are homogeneous gray granites. Only G1 granite 
presents a kind of planar anisotropy materialized by tiny sub-parallel cracks. G1 presents coarse granular texture, G2 presents a porphyritic facies with feldspar phenocrysts in a medium to coarse granular mesostasis, and G3 presents a weak porphyritic trend given by some feldspar crystals slightly larger than the grains of the medium granular mesostasis. The mineralogical composition of these granites is gray vitreous quartz ( 25 to $30 \%$ vol.), white K-feldspar (mainly orthoclase and microcline), and plagioclase (oligoclase) which together account for 50 to $60 \%$ volume (Fig. 3); the feldspars are frequently affected by hydrothermal processes of sericitization which are more extensive in G1 facies. Brown biotite is always the most representative mica (about 10\% vol.); some crystals show partial (hydrothermal) alteration to chlorite and/or muscovite, mostly along cleavage plans. Microscopic analysis has also shown the presence of accessory minor phases, such as apatite and zircon.

All limestones (C1, C2, and C3) present very good cohesion and consistency. In C1 stylolites are not identified while in $\mathrm{C} 2$ and $\mathrm{C} 3$ some of these surfaces can be observed. Limestone $\mathrm{C} 1$ presents homogeneous light cream color sparsely dotted by millimeter size gray, brown or dark cream color irregular fragments (Fig. 2). Limestone $\mathrm{C} 2$ shows bluish gray color with irregular fragments varying between 1 and $10 \mathrm{~mm}$ in size (Fig. 2). Limestone C3 presents light cream color with bright yellowish orange lines corresponding to fossil fragments that define the sedimentary bed. The nature of the carbonate rocks is predominantly calcitic (Fig. 3). C1 is a biosparite; C2, with percentages over $25 \%$ of oolites and sparry cement, is a oosparite; C3 highlights the abundance of fossil and the prominently crystalline nature of the cement, which also allows to classify it as a biosparite (Fig. 3). M1 is a fine to medium granoblastic calcite white marble (Fig. 2) with crystallographic preferred orientation (Figs. 2 and 3).

\section{Density and Porosity}

For completeness, bulk density and open porosity were also measured in the Cevalor Mechanical Tests Laboratory (LEM) using the European standard EN 1936. Bulk density and open porosity values are presented in Table 1.

Table 1: Mean values and standard deviations (s.d.) of the bulk density and the open porosity measured on the seven rock samples.

\begin{tabular}{|c|c|c|}
\hline \multirow{2}{*}{ REF } & $\begin{array}{c}\text { Bulk density } \\
{\left[\mathrm{kg} / \mathrm{m}^{3}\right]}\end{array}$ & $\begin{array}{c}\text { Open porosity } \\
{[\%]}\end{array}$ \\
\cline { 2 - 3 } & Mean \pm s.d. & Mean \pm s.d. \\
\hline G1 & $2570 \pm 7$ & $2.4 \pm 0.1$ \\
\hline G2 & $2640 \pm 10$ & $0.6 \pm 0.1$ \\
\hline G3 & $2620 \pm 5$ & $0.8 \pm 0.0$ \\
\hline M1 & $2710 \pm 5$ & $0.2 \pm 0.0$ \\
\hline C1 & $2570 \pm 0$ & $4.0 \pm 0.1$ \\
\hline C2 & $2660 \pm 0$ & $1.6 \pm 0.0$ \\
\hline C3 & $2660 \pm 14$ & $0.9 \pm 0.2$ \\
\hline
\end{tabular}



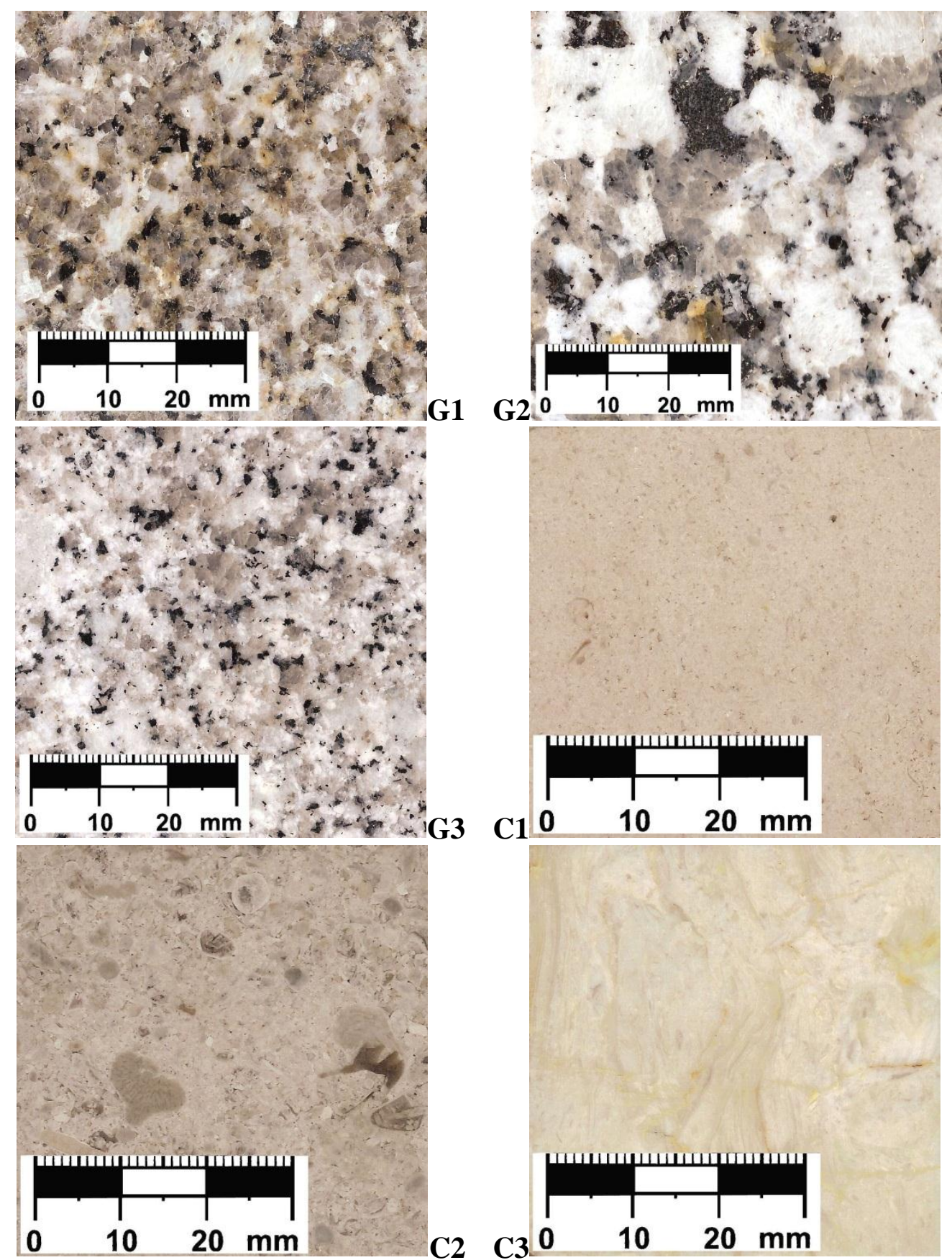

G3
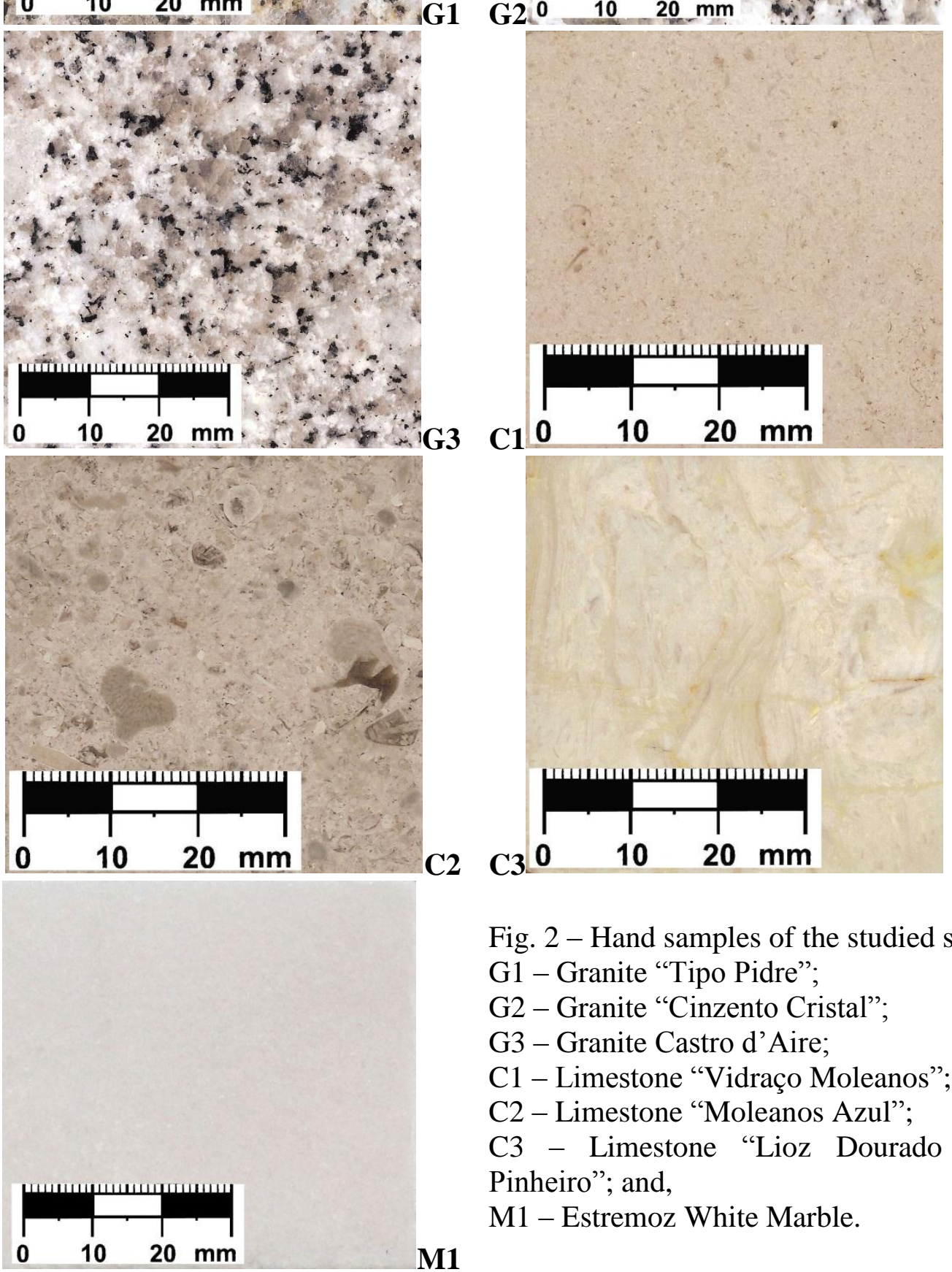

Fig. 2 - Hand samples of the studied stones:

G1 - Granite "Tipo Pidre";

G2 - Granite "Cinzento Cristal";

G3 - Granite Castro d'Aire;

C1 - Limestone "Vidraço Moleanos";

C2 - Limestone "Moleanos Azul";

C3 - Limestone "Lioz Dourado de Pêro Pinheiro"; and,

M1 - Estremoz White Marble. 

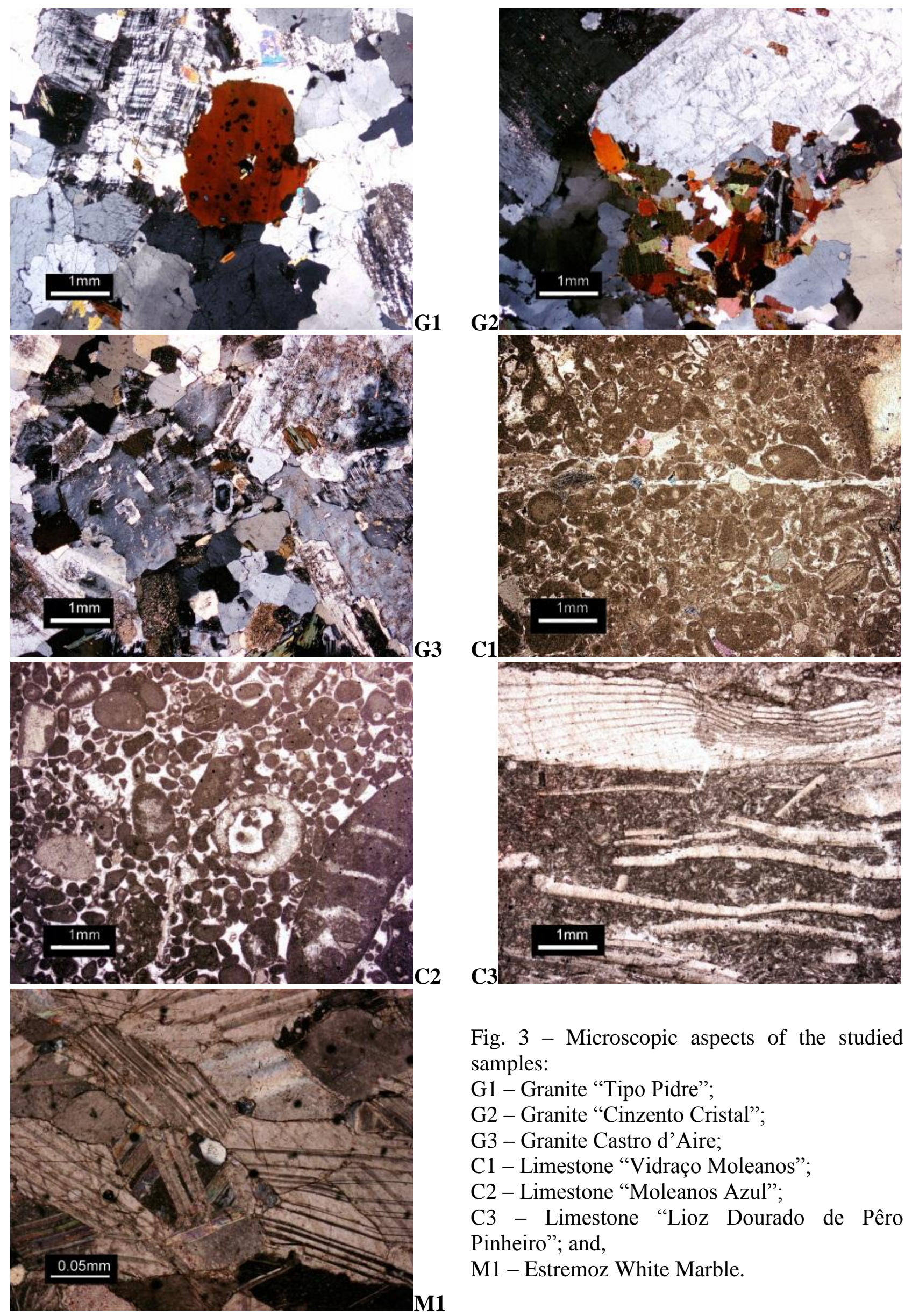

Fig. 3 - Microscopic aspects of the studied samples:

G1 - Granite "Tipo Pidre";

G2 - Granite "Cinzento Cristal";

G3 - Granite Castro d'Aire;

C1 - Limestone "Vidraço Moleanos";

C2 - Limestone "Moleanos Azul";

C3 - Limestone "Lioz Dourado de Pêro

Pinheiro"; and,

M1 - Estremoz White Marble. 


\section{Thermal Properties}

Thermal conductivity, thermal diffusivity, and specific heat were measured in the seven rock samples of this study in the Geothermics Laboratory of Geophysical Centre of Évora with an ISOMET 2104 Heat Transfer Analyser (Fig. 4) which allows measuring the three properties simultaneously. The thermal probe used to make the measurements has a range between 2.00 and $6.00 \mathrm{~W} / \mathrm{mK}$. The average values for the thermal conductivity, the thermal diffusivity, and the specific heat of the seven samples were obtained by placing the probe in different places on the polished surface of each of them. The calculated average values as well as the standard deviations are presented in Table 2.

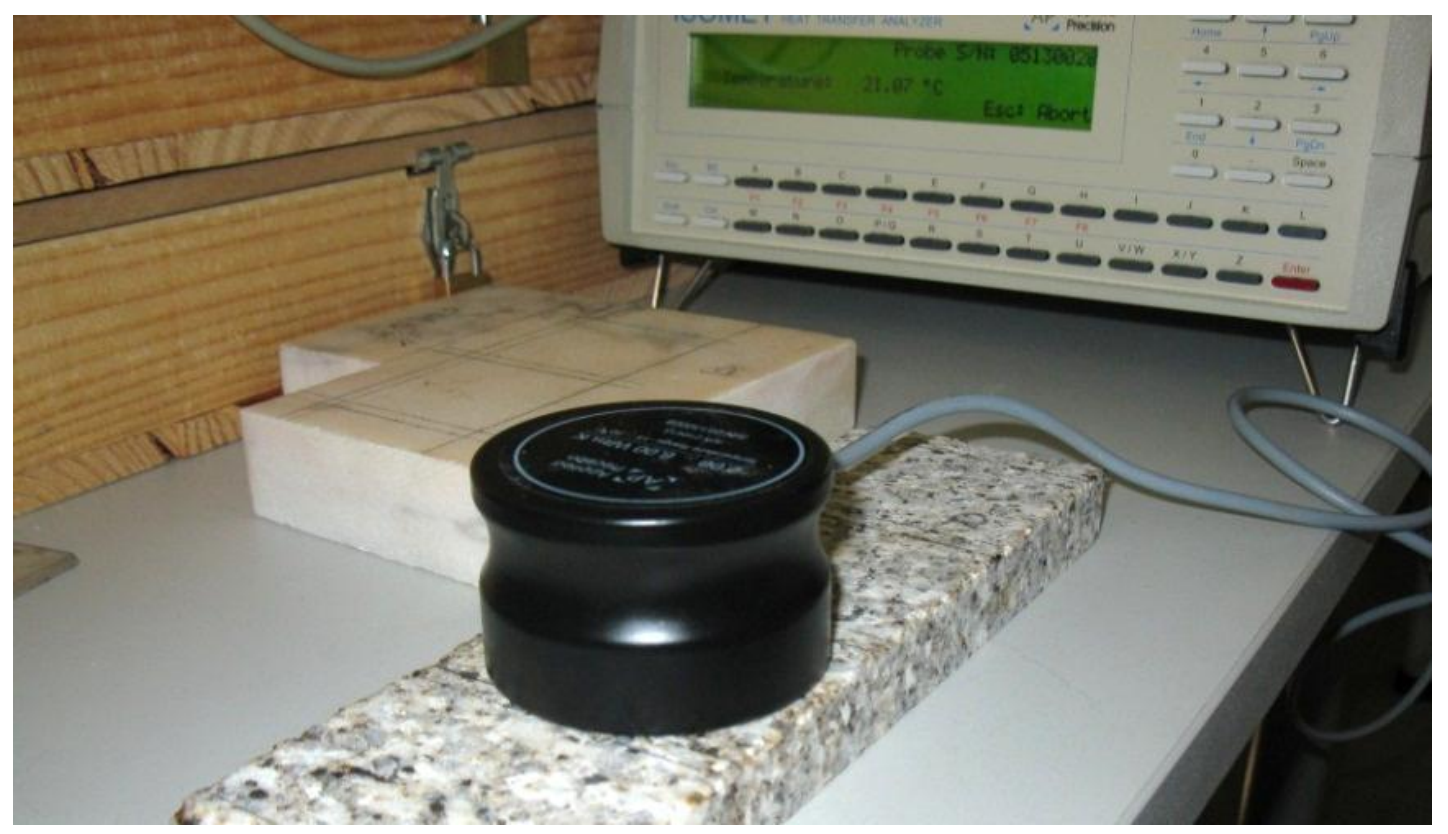

Fig. 4 - Heat Transfer Analyser ISOMET 2104. The measuring probe is the black device on top of the rock sample.

Table 2: Values of the thermophysical properties measured on granites (G1, G2, and G3), marble (M1), and limestones (C1, C2, and C3) with the ISOMET 2104 using a surface probe (range between 2.00 and $6.00 \mathrm{~W} / \mathrm{mK}$ ). REF - Sample reference; TC - Thermal conductivity; TD -Thermal diffusivity; VHC - Volumetric heat capacity. N - Number of measurements per sample.

\begin{tabular}{|c|c|c|c|c|c|c|}
\hline \multirow{2}{*}{ REF } & \multicolumn{2}{|c|}{$\begin{array}{c}\text { TC } \\
{[\mathrm{W} / \mathrm{mK}]}\end{array}$} & \multicolumn{2}{c|}{$\begin{array}{c}\text { TD } \\
{\left[\times 10^{-6} \mathrm{~m}^{2} / \mathrm{s}\right]}\end{array}$} & \multicolumn{2}{c|}{$\begin{array}{c}\text { VHC } \\
{\left[\times 10^{6} \mathrm{~J} / \mathrm{m}^{3} \mathrm{~K}\right]}\end{array}$} \\
\cline { 2 - 7 } & $\mathrm{N}$ & Mean \pm s.d. & $\mathrm{N}$ & Mean \pm s.d. & $\mathrm{N}$ & Mean \pm s.d. \\
\hline $\mathrm{G} 1$ & 16 & $3.24 \pm 0.21$ & 16 & $1.55 \pm 0.12$ & 16 & $2.10 \pm 0.04$ \\
\hline $\mathrm{G} 2$ & 12 & $2.92 \pm 0.21$ & 12 & $1.32 \pm 0.09$ & 12 & $2.22 \pm 0.06$ \\
\hline $\mathrm{G} 3$ & 16 & $2.98 \pm 0.09$ & 16 & $1.32 \pm 0.03$ & 16 & $2.26 \pm 0.04$ \\
\hline M1 & 9 & $2.90 \pm 0.03$ & 9 & $1.31 \pm 0.03$ & 9 & $2.22 \pm 0.07$ \\
\hline $\mathrm{C} 1$ & 6 & $2.77 \pm 0.02$ & 6 & $1.26 \pm 0.01$ & 6 & $2.20 \pm 0.01$ \\
\hline $\mathrm{C} 2$ & 8 & $3.04 \pm 0.05$ & 8 & $1.31 \pm 0.01$ & 8 & $2.32 \pm 0.04$ \\
\hline $\mathrm{C} 3$ & 6 & $3.07 \pm 0.03$ & 6 & $1.42 \pm 0.03$ & 6 & $2.16 \pm 0.05$ \\
\hline
\end{tabular}


Thermal conductivity (in $\mathrm{W} / \mathrm{mK}$ ) is a thermal property that quantifies the ability of a rock to allow heat to go through it; it has to do with stationary heat flow and the higher its value the better heat flows through a rock. Thermal diffusivity (in $\mathrm{m}^{2} / \mathrm{s}$ ) reflects the ability of a rock to absorb and release heat; it has to do with non-stationary heat flow and the higher its value the better heat is absorbed or released from it. Specific heat $\left(\mathrm{J} / \mathrm{m}^{3} \mathrm{~K}\right)$ represents the amount of heat a rock can accumulate and the higher its value the bigger the amount of heat it can accumulate.

In general terms, thermal conductivity depends on open porosity, bulk density, mineralogy, anisotropy and size of the crystals, pressure, and temperature. Thermal diffusivity $(\alpha)$ depends on the thermal conductivity $(\mathrm{K})$, the bulk density $(\rho)$, and the specific heat capacity $(\mathrm{C})$ of the rock through the equation (1) [1]:

$$
\alpha=\frac{\mathrm{K}}{\rho \mathrm{C}}
$$

\section{Radioactivity of Rocks as a Thermal Property}

Dimension stones are building materials used in civil engineering and architecture. There have been lately reports raising some concerns about radioactivity of the rocks used inside houses and apartments [2, 3, 4]. As a matter of fact, granitic rocks can present high contents of uranium and thorium that are the main sources of radon which can be harmful to human health. As a result of the radioactive series decay from ${ }^{235} \mathrm{U},{ }^{238} \mathrm{U}$, and ${ }^{232} \mathrm{Th}$ radon can occur as three natural nuclides ${ }^{219} \mathrm{Rn}$,

${ }^{222} \mathrm{Rn}$, and ${ }^{220} \mathrm{Rn}$, respectively. Apparently, because of its half-life of 3.82 days, ${ }^{222} \mathrm{Rn}$ is the only nuclide that can migrate and attain high concentrations in non-ventilated closed spaces. Even though it is not a usual practice to measure the concentrations of uranium, thorium and potassium in rocks for civil engineering purposes, it appears that it should be implemented as a routine procedure. The Geophysical Centre of Évora has now the capability of determining the concentrations of uranium, thorium and potassium in rock samples so that estimates of radon produced by radioactive decay can be done.

\section{Discussion and Conclusions}

The measurement of thermal properties of rocks, in general, and dimension stones, in particular, is important to determine the kind of purposes those rocks can be applied to. As a matter of fact, the characteristics of the rocks have to comply with requirements from national and international regulations concerning the quality and safety of building materials. Thermal properties such as thermal conductivity, thermal diffusivity, and specific heat are important for thermal comfort inside houses and apartments while radon concentration is important in terms of several types of cancer prevention. Furthermore, since there is an increase demand for more efficient use of energy, the fact that a rock can be characterized in terms of its ability to accumulate heat during night hours (when the demand of electricity is low) and release heat (when the demand of electricity is high) suggests that rocks can be used to improve indoor climatization with efficiency gains. Besides, dimension stones are also a good source of art work and decoration, and, therefore, can also be used for visual comfort. This means that rocks can be used as decorating efficient heat exchangers.

However, rocks can also be a source of diseases, in particular related with cancer as a result of high concentrations of radon resulting from radioactive decay of uranium and thorium present in many types of granite. So, to avoid health problems care should be taken when those rocks are used as building materials. With those two aspects in mind, routine measurements of thermal and radioactive properties of rocks should be implemented.

In terms of the measurements presented in this study, it is possible to say that rocks can be classified (in a qualitative way) as good or bad by measuring the thermal conductivity, the bulk density, and the open porosity, as shown in Table 3. Even though the thermal conductivity values vary little amongst the seven rock samples of this study, comparing the quality values shown in Table 3 with the measured values in Table 2 it is possible to notice that the samples $\mathrm{G} 1$ and $\mathrm{C} 1$ have 
characteristics less desirable as building materials. The bulk density values for G1 and $\mathrm{C} 1$ samples are within the average values considered for rock quality for building purposes, whereas the other values are near the values for high quality rocks (Table 3). The open porosity values for G1 and C1 are near the average values for rock quality; in contrast, the other rocks have a low to a very low open porosity value. As a summary, for the seven rocks of this study the marble presents the best quality based on the physical properties measured. In the same way, granites G2 and G3 present an average quality as well as the limestone $\mathrm{C} 3$, which, amongst the limestones of this study, presents the best quality values for civil construction purposes.

Table 3: Quality ranking of rocks to be used for building purposes in terms of thermal conductivity, bulk density, and open porosity. Bulk density and open porosity adapted from [5]. The arrow points increasing quality.

\begin{tabular}{|c|c|c|c|}
\hline Quality trend & Thermal conductivity $[\mathrm{W} / \mathrm{mK}]$ & Bulk density $\left[\mathrm{kg} / \mathrm{m}^{3}\right]$ & Open porosity [\%] \\
\hline \multirow{3}{*}{} & Very high $(>4.0)$ & Very low $(<2300)$ & Very high $(>10.0)$ \\
\cline { 2 - 4 } & High (4.0) & Low $(2300-2560)$ & High $(10.0-6.0)$ \\
\cline { 2 - 4 } & Medium & Medium $(2600-2700)$ & Medium $(3.0-1.0)$ \\
\cline { 2 - 4 } & Low $(0.3)$ & High $(2700-2800)$ & Low $(1.0-0.5)$ \\
\cline { 2 - 4 } & Very low $(<0.3)$ & Very high $(>2800)$ & Very low $(\leq 0.5)$ \\
\hline
\end{tabular}

\section{Acknowledgements}

The authors express their gratitude to Granimarante Lda. and Joaquim Duarte Urmal \& Filhos Lda. for permission to use the bulk density data and the open porosity data presented in this study.

\section{References}

[1] J.H. Schön, in: Physical properties of rocks: fundamentals and principles of petrophysics, Handbook of geophysical exploration, Section I, Seismic exploration: v 18, Pergamon (1996).

[2] S. Darby, D. Hill, A. Auvinen, J.M. Barros-Dios, H. Baysson, F. Bochicchio, H. Deo, R. Falk, F. Forastiere, M. Hakama, I. Heid, L. Kreienbrock, M. Kreuzer, F. Lagarde, I. Mäkeläinen, C. Muirhead, W. Oberaigner, G. Pershagen, A. Ruano-Ravina, E. Ruosteenoja, A. Schaffrath Rosario, M. Tirmarche, L. Tomásek, E. Whitley, H. E. Wichmann, R. Doll: Radon in homes and risk of lung cancer: collaborative analysis of individual data from 13 European casecontrol studies, Br. Med. J. 330 (7485) (2005) pp. 223-226.

[3] S.D. Krewski, J.H. Lubin, J.M. Zielinski, M. Alavanja, V.S. Catalan, R.W. Field, J.B. Klotz, E.G. Le'tourneau, C.F. Lynch, J.I. Lyon, D.P. Sandler, J.B. Schoenberg, D.J. Steck, J.A. Stolwijk, C. Weinberg, and H.B. Wilcox: Residential radon and risk of lung cancer: a combined analysis of 7 North American case-control studies. Epidemiology 16 (2) (2005) pp. 137-145.

[4] L.L. Chyi, in: Radon Testing of Various Countertop Materials, University of Akron, Akron (2008).

[5] A.M.E. Henriques and J.M.S.N. Tello: Manual da Pedra Natural para a Arquitectura, Direcção Geral de Geologia e Energia, Lisboa (2006). 